\title{
GENETIC ENHANCEMENT OF SUGARCANE (Saccharum sp. hybrids) FOR RESISTANCE TO RED ROT DISEASE AND ECONOMIC TRAITS
}

\author{
C. Babu ${ }^{1}$, K. Koodalingam ${ }^{1}$, U.S. Natarajan ${ }^{2}$, R.M. Shanthi ${ }^{2}$ and P. Govindaraj ${ }^{2}$
}

ABSTRACT

The present experiment was conducted at Sugarcane Breeding Institute (ICAR), Coimbatore to generate diverse genetic stocks for resistance to red rot disease caused by Colletotrichum falcatum Went. and other important economic traits. This study was carried out with progenies obtained from 39 crosses involving 45 parental clones of interspecific and intervarietal origin. The interspecific origin involves diverse forms of Saccharum officinarum and $S$. spontaneum that are hitherto unutilized in the breeding programme. The progenies were evaluated for resistance to red rot disease and economic traits such as cane yield and quality. Out of 39 crosses investigated for race specific resistance as a qualitative trait, 18 crosses showed a simple Mendelian segregation of monogenic nature. Parent progeny regression analysis suggested that about 50\% of the variation in the population could be attributed to additive genetic variance (horizontal resistance). Two crosses involving susceptible parents viz., 971235 (S) x Co 1148 (S) and Co 88028 (S) x Co 775 (S) contributed 28-30\% resistant progenies. These transgressive segregants are likely to be stable in their resistance due to additive genetic action and could be used as donor parents in red rot resistance breeding programmes for imparting race non-specific resistance. The present investigation has also identified some specific cross combinations for yield, quality in addition to red rot resistance for further exploitation in breeding programme.

Key words: Genetic enhancement, Saccharum sp. hybrids, red rot resistance

\section{INTRODUCTION}

Present day sugarcane cultivars are descendants of trispecific hybrids of Saccharum officinarum, Saccharum barberi / sinense and Saccharum spontaneum and derive their ability to produce cane and sugar from the first, disease resistance, hardiness and ability to withstand adverse conditions from the third species. $S$. barberi / sinense, being considered to be derivatives of natural hybridization between S. officinarum and S. spontaneum (Parthasarathy, 1946) might have contributed gene complexes for adaptiveness and sucrose content. The genetic variability created through interspecific hybridization and back crossing by these major species has sustained the sugarcane improvement activities for more than half-a-century. Further improvement within this population essentially depends on the release and the utilization of variability available for stalk yield and quality traits. Proper exploitation of this variability in a crop like sugarcane with a complex ploidy nature and high level of heterozygosity is a complicated process. Breeding for higher yield and quality requires basic information on the extent of genetic variation in a population and its response to selection.

The first Indian commercial hybrid cane Co 205 was an interspecific hybrid between $S$. officinarum Vellai and $S$. spontaneum Coimbatore (Barber, 1920).

${ }^{I}$ Centre for Plant Breeding and Genetics, Tamil Nadu Agricultural University, Coimbatore 641 003, Tamil Nadu, India.

${ }^{2}$ Plant Breeding Section, Division of Crop Improvement, Sugarcane Breeding Institute (ICAR), Coimbatore-641 007, Tamil Nadu, India. 
Subsequently $S$. barberi, $S$. sinense and the wild species $S$. spontaneum were utilized, along with $S$. officinarum for evolving commercial hybrids in India (Venkatraman, 1938). After the initial interspecific crosses, sugarcane breeders concentrated their attention on intercrossing of their derivatives. This has resulted in further improvement in yield and quality of commercial hybrid cane varieties. The present day varieties have a narrow genetic base with only $11 S$. officinarum and $2 \mathrm{~S}$. spontaneum clones (Natarajan, 1984).

Characterization of the parents allows the calculation of genetic distances, which may have predictive value for the offsprings, to that extent as dominant gene action plays a major role in controlling the agronomically important traits for exploiting heterosis. Since most of the present day varieties are the product of a few selected original germplasm and further improvement through selection for per se performance of a few meiotic recombinant progenies, total genetic recombination present in the modern varieties is limited. Because of the small number of clones / species used in primary crosses, genetic base of modern sugarcane varieties has been reported to be narrow and is thought to be the reason for the present slow progress in sugarcane breeding (Arceneaux, 1965 and D'Hont et al., 1995). Concern has also been expressed in this regard to the overall reduction of the gene pool available for sugarcane improvement. This necessitates the sugarcane breeders to explore new possibilities to increase genetic variability by identifying and effecting crosses between the diverse parents.Red rot caused by Colletotrichum falcatum went, is the most serious disease of sugar cane in India. It is also the oldest mentioned disease of sugarcane dating back to the times of Buddha. Barber in 1901 made the first recorded report of red rot occurrence in India. Since then a number of red rot epidemics have been reported, especially in eastern Uttar Pradesh, northern Bihar and pockets of Punjab. These epidemics have resulted in the devastation of local varieties and elimination of many early Coimbatore bred varieties including $\mathrm{Co}$ 312 and Co 453. In recent times, CoJ 64, which had been the most popular variety because of its highest recovery, was one among the several varieties that succumbed to red rot. The disease essentially confined to northern India and parts of north-western India and Andhra Pradesh for several decades has started spreading to other parts of southern India as well, especially in the east coast zone, taking a heavy toll of many improved varieties, the most notable one being $\mathrm{CoC}$ 671 (Natarajan et al. 1998). As a consequence breeding for red rot resistance has emerged as an important facet of varietal evolution. In the present study, crosses have been made using parents from interspecific origin involving diverse forms of $S$. officinarum and $S$. spontaneum that are hitherto unutilized in the sugarcane breeding programme.

\section{MATERIALS AND METHODS}

\section{Experimental materials}

The experimental materials consisted of 1950 progenies obtained from 39 biparental crosses involving 11 pollen parents and 34 pistil parents of sugarcane. Present study was conducted at Sugarcane Breeding Institute (ICAR), Coimbatore, India (latitude; $11^{\circ}$ North; longitude; $78^{\circ} .8^{\prime}$ East; altitude; $426.72 \mathrm{~m} \mathrm{MSL}$ ) during 2002-2003.

The parental materials include clones released from Sugarcane Breeding Institute, Coimbatore, state Sugarcane Research Stations and promising clones selected from various research projects of Sugarcane Breeding Institute, Coimbatore. Out of these, 17 clones are derived from interspecific hybridization between $S$. officinarum and S. spontaneum. These 
diverse S. officinarum and S. spontaneum clones (6 each) are so far unused in sugarcane breeding programmes and thus provide much needed genetic diversity in the parent materials. The list of such interspecific parents and the $S$. officinarum and $S$. spontaneum clones involved in their constitution is given in Table 1 .

Table 01: Interspecific origin of the parents used in the study

\begin{tabular}{|c|c|c|c|}
\hline \multirow{2}{*}{ S.No. } & \multirow{2}{*}{ Parents } & \multicolumn{2}{|c|}{ Species involved } \\
\hline & & Saccharum officinarum & Saccharum spontaneum \\
\hline 1 & 970311 & 28 NG 210, NG 77-99 & SES 87A \\
\hline 2 & 971235 & - & SES 275 \\
\hline 3 & 971236 & - & SES 275 \\
\hline 4 & 973402 & $\begin{array}{l}\text { NG 77-99, } 28 \text { NG 51, } \\
\text { NG 77-63, NG 77-137 }\end{array}$ & SES 44A, SES 538 \\
\hline 5 & 9844195 & $\begin{array}{l}28 \text { NG } 221 \text {, NG } 77-99 \\
28 \text { NG } 51,28 \text { NG } 210 \text {, } \\
\text { NG } 77-137\end{array}$ & $\begin{array}{l}\text { SES 515-7, SES 44A, } \\
\text { SES } 538\end{array}$ \\
\hline 6 & 984727 & $28 \mathrm{NG} 221$ & SES 91, SES 515-7 \\
\hline 7 & 984819 & $28 \mathrm{NG} 221$ & SES 515-7 \\
\hline 8 & 984843 & $28 \mathrm{NG} 221$ & SES 515-7 \\
\hline 9 & 985040 & 28 NG 221 & SES 515-7 \\
\hline 10 & 985094 & 28 NG 221 & SES 515-7 \\
\hline 11 & 985735 & 28 NG 221 & SES $44 \mathrm{~A}$ \\
\hline 12 & 985931 & - & SES 91 \\
\hline 13 & 986046 & - & SES 91 \\
\hline 14 & 986095 & - & SES 91 \\
\hline 15 & 986140 & - & SES 91 \\
\hline 16 & 986179 & - & SES 91 \\
\hline 17 & 9869110 & $\begin{array}{l}\text { NG 77-99, } 28 \text { NG 51, } \\
28 \text { NG } 210, \text { NG } 77-137\end{array}$ & SES 44A, SES 538 \\
\hline
\end{tabular}

SES - Saccharum spontaneum Expedition Scheme

NG - New Guinea

Out of these 39 biparental crosses, 23 crosses involved interspecific derivatives as parents as against 16 crosses which involved only intervarietal derivatives as parents. Thirty six seedlings per replication per cross were planted in a randomized block design with 12 seedlings per row of $6 \mathrm{~m}$ length along with the parents. Normal package of practices were adopted. 


\section{Biometrical observations}

All the progenies along with their corresponding parents were subjected to screening against red rot disease under controlled condition testing (CCT) method as suggested by Mohanraj et al. (1994 and 1997) and Viswanathan et al. (1998). At the age of tenth month single healthy stalk from each selected progeny was cut at the bottom and brought to the testing chamber. Then the top portion of the cane with 5-6 internodes retaining the 3-4 last emerged leaves was cut and the leaf sheaths were removed using a fine knife without injuring the nodal tissues. The top two nodes were then covered with cotton. Two canes were used for testing in the case of parents. Inoculum from the Colletotrichum falcatum pathotypes isolated from the infected canes of $\mathrm{CoC} 671$ was used for disease evaluation and the spore suspension was poured over the nodes wrapped with cotton. The inoculated canes were then placed vertically in a sand medium and allowed to root and remain metabolically active in the chamber. They were incubated in moist chamber under $90 \%$ relative humidity and the temperature was maintained at $32^{\circ} \mathrm{C}$ for 7-10 days.

\section{Disease Rating}

A week to 10 days after inoculation disease reaction was scored as levels of resistance on a scale of 1 to 5 based on the criteria reported earlier as 1 - highly susceptible (HS), 2 susceptible (S), 3 - moderately susceptible (MS), 4 - moderately resistant (MR) and 5 - resistant (R) (Mohanraj et al. 1997). The average of two observations was taken for analysis in parents.

\section{Data Analyses}

The disease scorings obtained from the different progenies were statistically analyzed to estimate the vertical (race specific) and horizontal (race non-specific) resistant components present in the population. The progenies of different crosses were grouped into two categories, resistant ( $\mathrm{R}$ and MR) and susceptible (MS, $\mathrm{S}$ and HS) for investigating race specific resistance (Mendelian). $\chi^{2}$ test for goodness of fit was worked out for monogenic inheritance. From the disease scorings (1, 2, 3, 4 and 5) of the progenies and parents, family mean and mid parental values were calculated, and parent progeny regression was arrived to find out the proportion of horizontal resistant component present in the population. The biometrical observations on economic traits such as sucrose per cent (SUC) and stalk yield per clump (YLD) at 360 days after planting were also recorded in the parents and their progenies in addition to the red rot resistance score. Sucrose per cent was determined by polarizing the juice, clarified with basic lead sub-acetate. A $200 \mathrm{~mm}$ observation tube was filled with the clear filtrate and placed in the Polariscope. The reading after adjusting the refracted light was noted. The percent pol was taken from Schmitz's table corresponding to the Brix value. The stalk yield per clump was calculated by multiplying the single stalk weight with number of millable stalks per clump at 360 days.

\section{RESULTS AND DISCUSSION}

The data collected on the disease scorings of individual progenies and parents was statistically analysed and the results on the mode of inheritance of red rot resistance were reported in terms of race specific (vertical resistance) and race non-specific (horizontal resistance) resistance.Out of the seven crosses tested under $\mathrm{R} \times \mathrm{R}$ category two crosses showed goodness of fit for 3:1 segregation while there were significant deviations in the other five crosses (Table 2).

However, in $\mathrm{R} \times \mathrm{S}$ category out of the 19 crosses, the expected ratio of 1:1 was observed in 16 crosses, the other three showing significant deviation. In the $\mathrm{S} x \mathrm{~S}$ category 13 crosses were studied. 
Although all progenies were expected to be susceptible according to Mendelian segregation, frequent occurrence of resistant progenies was also observed.

Table 02: Pattern of Mendelian segregation for red rot resistance

\begin{tabular}{|c|c|c|c|c|}
\hline S.No. & Cross & $\begin{array}{c}\quad \mathbf{R} ' \\
\text { progenies }\end{array}$ & $\begin{array}{c}\text { 'S' } \\
\text { progenies }\end{array}$ & $\chi^{2}$ \\
\hline \multicolumn{5}{|c|}{$\mathbf{R} \times \mathbf{R}(3: 1)$} \\
\hline 1 & Co $87002[\mathrm{R}]$ x 986179 [R] & 13 & 21 & $13.57 * *$ \\
\hline 2 & CoM 9220 [R] x 984843 [R] & 21 & 15 & $5.33^{*}$ \\
\hline 3 & CoM 9220 [R] x $987001[\mathrm{R}]$ & 21 & 15 & $5.33^{*}$ \\
\hline 4 & ISH $1[\mathrm{R}]$ x Co $94008[\mathrm{R}]$ & 14 & 17 & $14.72 * *$ \\
\hline 5 & RS 93-2182 [R] x Co $93009[\mathrm{R}]$ & 26 & 6 & 0.67 \\
\hline 6 & $9844195[\mathrm{R}]$ x Co A7602 [R] & 19 & 17 & $9.48^{* *}$ \\
\hline 7 & $987032[\mathrm{R}] \times$ x Co $93009[\mathrm{R}]$ & 28 & 4 & 2.67 \\
\hline \multicolumn{5}{|c|}{$\operatorname{Rx} S(1: 1)$} \\
\hline 8 & Co $8371[\mathrm{~S}]$ x $971862[\mathrm{R}]$ & 7 & 29 & $13.44 * *$ \\
\hline 9 & Co $85002[\mathrm{~S}]$ x $971862[\mathrm{R}]$ & 18 & 18 & 0 \\
\hline 10 & Co $86010[\mathrm{R}]$ x Co $775[\mathrm{~S}]$ & 13 & 23 & 2.78 \\
\hline 11 & Co $86249[\mathrm{R}] \times$ Co $775[\mathrm{~S}]$ & 12 & 23 & 3.46 \\
\hline 12 & Co $98003[\mathrm{~S}]$ x 971862 [R] & 19 & 17 & 0.10 \\
\hline 13 & Co $98006[\mathrm{~S}]$ x $987001[\mathrm{R}]$ & 21 & 15 & 1.00 \\
\hline 14 & CoC $671[\mathrm{~S}] \times$ Co $94008[\mathrm{R}]$ & 11 & 23 & $4.24 *$ \\
\hline 15 & $\mathrm{CoH} 110$ [S] x 984843 [R] & 22 & 14 & 1.78 \\
\hline 16 & $\mathrm{CoH} 110[\mathrm{~S}]$ x $986179[\mathrm{R}]$ & 19 & 17 & 0.10 \\
\hline 17 & $87 \mathrm{~A} 298[\mathrm{R}]$ x Co $1148[\mathrm{~S}]$ & 14 & 22 & 1.78 \\
\hline 18 & $970311[\mathrm{~S}] \times 986179[\mathrm{R}]$ & 17 & 19 & 0.10 \\
\hline 19 & $973402[\mathrm{R}] \times$ Co $775[\mathrm{~S}]$ & 11 & 22 & 3.66 \\
\hline 20 & $984727[\mathrm{~S}]$ x $984843[\mathrm{R}]$ & 6 & 30 & $16.00 * *$ \\
\hline 21 & $984819[\mathrm{R}] \times$ x Co $1148[\mathrm{~S}]$ & 21 & 14 & 1.40 \\
\hline 22 & $985931[\mathrm{R}] \times$ Co $775[\mathrm{~S}]$ & 21 & 15 & 1.00 \\
\hline 23 & $986095[\mathrm{~S}]$ x Co 94008 [R] & 16 & 19 & 0.26 \\
\hline 24 & $9869110[\mathrm{R}] \times$ Co $1148[\mathrm{~S}]$ & 20 & 16 & 0.44 \\
\hline 25 & $9869110[\mathrm{R}]$ x Co $62198[\mathrm{~S}]$ & 11 & 22 & 3.66 \\
\hline 26 & $987080[\mathrm{R}] \times$ Co $1148[\mathrm{~S}]$ & 19 & 15 & 0.48 \\
\hline \multicolumn{5}{|c|}{$\mathbf{S} \times \mathbf{S}$} \\
\hline 27 & $971235[\mathrm{~S}] \times \mathrm{C}$ Co $1148[\mathrm{~S}]$ & 11 & 25 & \\
\hline 28 & $971235[\mathrm{~S}]$ x Co $62198[\mathrm{~S}]$ & 4 & 32 & \\
\hline 29 & $971236[\mathrm{~S}]$ x Co $62198[\mathrm{~S}]$ & 5 & 31 & \\
\hline 30 & Co $88028[S] \times$ Co $775[S]$ & 10 & 26 & \\
\hline 31 & $\mathrm{CoH} 76[\mathrm{~S}] \times \mathrm{x} 985094[\mathrm{~S}]$ & 3 & 32 & \\
\hline 32 & CoJ $72[\mathrm{~S}] \times$ Co $62198[\mathrm{~S}]$ & 1 & 35 & \\
\hline 33 & $985040[\mathrm{~S}] \times$ Co $1148[\mathrm{~S}]$ & 2 & 34 & \\
\hline 34 & $985735[\mathrm{~S}]$ x Co $62198[\mathrm{~S}]$ & 2 & 20 & \\
\hline 35 & $986046[\mathrm{~S}]$ x Co $775[\mathrm{~S}]$ & 6 & 29 & \\
\hline 36 & $986095[\mathrm{~S}]$ x Co $62198[\mathrm{~S}]$ & 1 & 34 & \\
\hline 37 & $986140[\mathrm{~S}] \times$ Co $1148[\mathrm{~S}]$ & - & 34 & \\
\hline 38 & $987124[\mathrm{~S}] \times \mathrm{Co} 775[\mathrm{~S}]$ & 3 & 33 & \\
\hline 39 & $9871144[\mathrm{~S}] \times$ Co $775[\mathrm{~S}]$ & 4 & 31 & \\
\hline
\end{tabular}

The family wise mean values on mid parent and families are given in Table 3. Using the mean values on mid parent and family, linear regression was worked out. The results of the analysis of variance for regression showed that the linear 
regression was found to be significant. From the graphical representation (Fig. 1), it is clear that, nearly 50 per cent of the variation could be attributed to linearity.

Table 03: Red rot resistance scores of families

\begin{tabular}{|c|c|c|c|c|c|}
\hline \multirow{2}{*}{ S.No } & \multirow[b]{2}{*}{ Family } & \multirow{2}{*}{$\begin{array}{c}\text { No. of } \\
\text { progenies } \\
\text { tested }\end{array}$} & \multirow{2}{*}{$\begin{array}{l}\text { Percentage of } \\
\text { ' } R \text { ' progenies }\end{array}$} & \multicolumn{2}{|c|}{ Mean values } \\
\hline & & & & Family & $\begin{array}{c}\text { Mid } \\
\text { parent }\end{array}$ \\
\hline 1 & Co $87002[R]$ x $986179[R]$ & 34 & 38.2 & 2.94 & 4.00 \\
\hline 2 & CoM $9220[R]$ x $984843[R]$ & 36 & 58.3 & 3.64 & 4.00 \\
\hline 3 & CoM $9220[R]$ x $987001[R]$ & 36 & 58.3 & 3.39 & 4.00 \\
\hline 4 & ISH 1 [R] x Co 94008 [R] & 31 & 45.2 & 3.13 & 4.00 \\
\hline 5 & RS 93-2182 [R] x Co93009 [R] & 32 & 81.3 & 4.38 & 4.00 \\
\hline 6 & $9844195[\mathrm{R}]$ x Co A7602 [R] & 36 & 52.8 & 3.19 & 4.25 \\
\hline 7 & $987032[\mathrm{R}]$ x Co 93009 [R] & 32 & 87.5 & 3.88 & 4.25 \\
\hline 8 & Co $8371[\mathrm{~S}]$ x $971862[\mathrm{R}]$ & 36 & 19.4 & 2.56 & 3.00 \\
\hline 9 & Co $85002[\mathrm{~S}]$ x $971862[\mathrm{R}]$ & 36 & 50.0 & 3.22 & 3.00 \\
\hline 10 & Co $86010[R] \times$ Co $775[S]$ & 36 & 36.1 & 2.86 & 3.00 \\
\hline 11 & Co $86249[\mathrm{R}] \times$ Co $775[\mathrm{~S}]$ & 35 & 34.3 & 3.01 & 3.00 \\
\hline 12 & Co 98003 [S] x $971862[R]$ & 36 & 52.8 & 3.36 & 3.25 \\
\hline 13 & Co $98006[\mathrm{~S}]$ x $987001[\mathrm{R}]$ & 36 & 58.3 & 3.19 & 3.25 \\
\hline 14 & CoC $671[\mathrm{~S}]$ x Co 94008 [R] & 34 & 32.4 & 2.85 & 2.50 \\
\hline 15 & $\mathrm{CoH} 110[\mathrm{~S}]$ x $984843[\mathrm{R}]$ & 36 & 61.1 & 3.44 & 3.25 \\
\hline 16 & $\mathrm{CoH} 110[\mathrm{~S}]$ x $986179[\mathrm{R}]$ & 36 & 52.8 & 3.33 & 3.25 \\
\hline 17 & 87A298 [R] x Co $1148[S]$ & 36 & 38.9 & 2.64 & 3.50 \\
\hline 18 & $970311[\mathrm{~S}] \times 986179[\mathrm{R}]$ & 36 & 47.2 & 3.17 & 3.50 \\
\hline 19 & $973402[\mathrm{R}] \times$ Co $775[\mathrm{~S}]$ & 33 & 33.3 & 2.70 & 3.00 \\
\hline 20 & $984727[\mathrm{~S}]$ x $984843[\mathrm{R}]$ & 36 & 16.7 & 2.42 & 3.25 \\
\hline 21 & $984819[\mathrm{R}] \times$ x Co $1148[\mathrm{~S}]$ & 35 & 60.0 & 3.40 & 3.50 \\
\hline 22 & $985931[\mathrm{R}]$ x Co $775[\mathrm{~S}]$ & 36 & 58.3 & 3.17 & 3.00 \\
\hline 23 & $986095[\mathrm{~S}] \times$ Co $94008[\mathrm{R}]$ & 35 & 45.7 & 3.17 & 3.50 \\
\hline 24 & $9869110[\mathrm{R}] \times$ Co $1148[\mathrm{~S}]$ & 36 & 55.6 & 3.25 & 3.50 \\
\hline 25 & $9869110[\mathrm{R}]$ x Co $62198[\mathrm{~S}]$ & 33 & 33.3 & 2.82 & 3.00 \\
\hline 26 & $987080[\mathrm{R}]$ x Co $1148[\mathrm{~S}]$ & 34 & 55.9 & 3.26 & 3.50 \\
\hline 27 & $971235[\mathrm{~S}]$ x Co $1148[\mathrm{~S}]$ & 36 & 30.6 & 2.72 & 2.50 \\
\hline 28 & $971235[\mathrm{~S}]$ x Co $62198[\mathrm{~S}]$ & 36 & 11.1 & 2.42 & 2.00 \\
\hline 29 & $971236[S] \times$ Co $62198[S]$ & 36 & 13.9 & 2.25 & 2.00 \\
\hline 30 & Co $88028[\mathrm{~S}]$ x Co $775[\mathrm{~S}]$ & 36 & 27.8 & 2.58 & 2.50 \\
\hline 31 & $\mathrm{CoH} 76[\mathrm{~S}]$ x $985094[\mathrm{~S}]$ & 35 & 8.6 & 2.37 & 2.75 \\
\hline 32 & CoJ $72[\mathrm{~S}]$ x Co $62198[\mathrm{~S}]$ & 36 & 2.8 & 1.80 & 2.50 \\
\hline 33 & $985040[\mathrm{~S}]$ x Co $1148[\mathrm{~S}]$ & 36 & 5.6 & 1.89 & 3.00 \\
\hline 34 & $985735[\mathrm{~S}] \times$ Co $62198[\mathrm{~S}]$ & 22 & 9.1 & 2.50 & 2.75 \\
\hline 35 & $986046[\mathrm{~S}]$ x Co $775[\mathrm{~S}]$ & 35 & 17.1 & 2.63 & 2.25 \\
\hline 36 & $986095[\mathrm{~S}] \times$ x Co $62198[\mathrm{~S}]$ & 35 & 2.9 & 1.86 & 2.50 \\
\hline 37 & $986140[\mathrm{~S}] \times$ x Co $1148[\mathrm{~S}]$ & 34 & 0.0 & 1.71 & 3.00 \\
\hline 38 & $987124[\mathrm{~S}] \times$ Co $775[\mathrm{~S}]$ & 36 & 8.3 & 2.31 & 2.00 \\
\hline 39 & $9871144[\mathrm{~S}] \times$ Co $775[\mathrm{~S}]$ & 35 & 11.4 & 2.20 & 2.25 \\
\hline
\end{tabular}




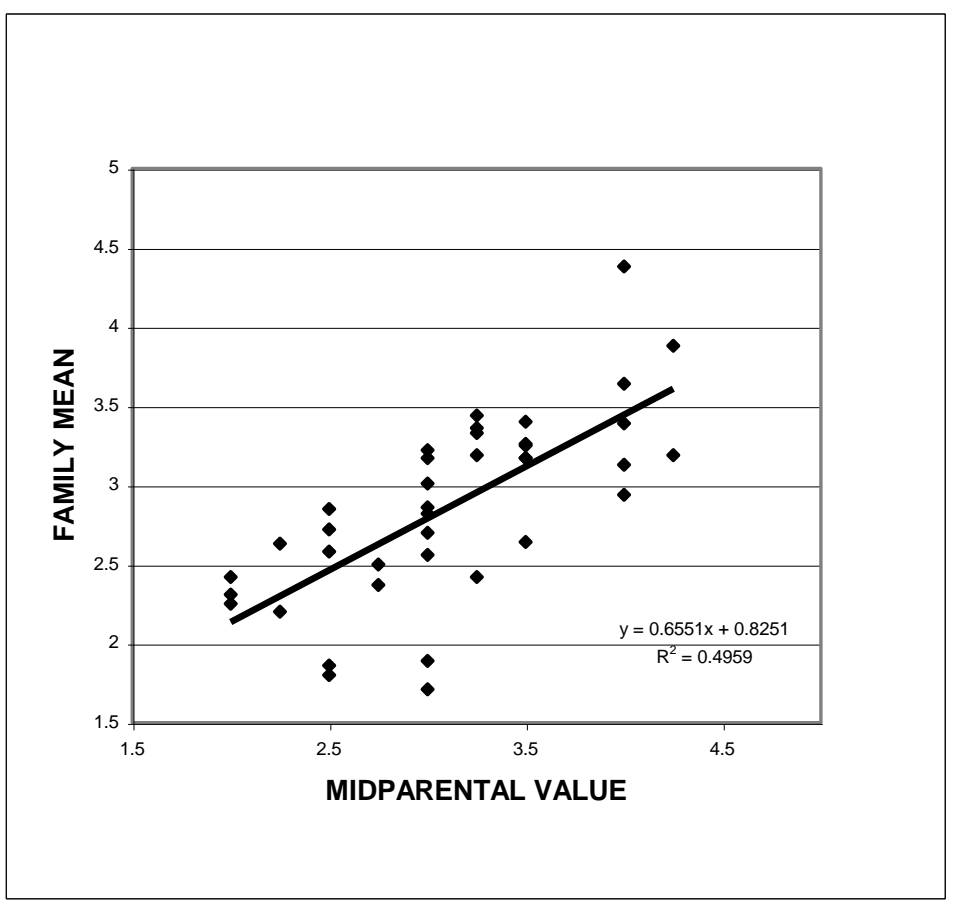

Figure 01: Parent-progeny regression for red rot resistance

Progenies combining yield and sucrose, yield and red rot resistance and all the three characters are also presented in the Table 4. It shows the percentage of progenies superior in performance over the general mean by one critical difference for clump yield, sucrose per cent and resistance to red rot disease.

\section{Inheritance of resistance}

Information on inheritance of red rot resistance in the present day varieties as well as in the advanced interspecific genetic stocks is essential to formulate appropriate breeding strategies The mode of inheritance was investigated both for race-specific and race non-specific components. It was found that out of seven crosses under R $\mathrm{x}$ R category, two crosses showed goodness of fit for 3:1 segregation while there were significant deviations in the other five crosses. Out of 19 crosses under $\mathrm{R} \times \mathrm{S}$ category, 1:1 segregation was observed in 16 crosses, the other three showing significant deviations. Natarajan et al. (2001a) studied inheritance of red rot in terms of vertical and horizontal resistance and reported that, 10 out of 20 crosses showed goodness of fit for simple Mendelian ratios and the rest displayed significant deviations.In the $S \times S$ category, 13 crosses were studied. Although all progenies are expected to be susceptible according to Mendelian segregation, frequent occurrence of resistant progenies was observed. This gave a clear indication that race specific resistance alone could not wholly explain the pattern of inheritance. Hence parentprogeny regression was worked out to find out the level of additive gene action (race non-specific) that confers red rot resistance. It was found that nearly $50 \%$ of the variation could be attributed to this component of resistance (Fig 1). Natarajan et al. (2001a) reported that, around 47 per cent of the variation observed was due to horizontal resistance. 
Table 04: Percentage of progenies in individual families superior to grand mean by at least one CD

\begin{tabular}{|c|c|c|c|c|c|c|c|}
\hline $\begin{array}{l}\text { S. } \\
\text { No. }\end{array}$ & Families & YLD & SUC & RRS & YLD+SUC & YLD+RRS & $\begin{array}{c}\text { YLD+SUC } \\
\text { + RRS }\end{array}$ \\
\hline 1 & Co 8371 x 971862 & 25 & 52 & 19 & 13 & 3 & 0 \\
\hline 2 & Co 85002 x 971862 & 27 & 75 & 50 & 16 & 14 & 11 \\
\hline 3 & Co $86010 \times$ Co 775 & 16 & 58 & 36 & 3 & 8 & 3 \\
\hline 4 & Co 86249 x Co 775 & 11 & 5 & 33 & 0 & 8 & 0 \\
\hline 5 & Co 87002 x 986179 & 17 & 26 & 38 & 0 & 9 & 0 \\
\hline 6 & Co 88028 x Co 775 & 16 & 41 & 27 & 8 & 11 & 5 \\
\hline 7 & Co 98003 x 971862 & 44 & 25 & 52 & 11 & 25 & 8 \\
\hline 8 & Co 98006 x 987001 & 27 & 22 & 58 & 5 & 22 & 8 \\
\hline 9 & CoC 671 x Co 94008 & 11 & 38 & 32 & 0 & 9 & 0 \\
\hline 10 & $\mathrm{CoH} 76$ x 985094 & 13 & 58 & 8 & 8 & 0 & 0 \\
\hline 11 & $\mathrm{CoH} 110$ x 984843 & 25 & 27 & 61 & 8 & 22 & 5 \\
\hline 12 & $\mathrm{CoH} 110$ x 986179 & 47 & 16 & 50 & 5 & 25 & 5 \\
\hline 13 & CoJ 72 x Co 62198 & 38 & 36 & 2 & 14 & 3 & 0 \\
\hline 14 & CoM 9220 x 984843 & 22 & 47 & 52 & 8 & 17 & 8 \\
\hline 15 & CoM 9220 x 987001 & 19 & 44 & 58 & 14 & 11 & 5 \\
\hline 16 & ISH 1 x Co 94008 & 29 & 9 & 41 & 0 & 5 & 0 \\
\hline 17 & RS 93-2182 x Co 93009 & 18 & 25 & 81 & 3 & 19 & 3 \\
\hline 18 & 87A298 x Co 1148 & 36 & 30 & 38 & 14 & 11 & 5 \\
\hline 19 & $970311 \times 986179$ & 16 & 13 & 47 & 0 & 8 & 0 \\
\hline 20 & 971235 x Co 1148 & 27 & 27 & 30 & 8 & 8 & 5 \\
\hline 21 & 971235 x Co 62198 & 22 & 80 & 11 & 14 & 3 & 2 \\
\hline 22 & 971236 x Co 62198 & 19 & 83 & 11 & 16 & 0 & 0 \\
\hline 23 & 973402 x Co 775 & 18 & 30 & 33 & 6 & 6 & 0 \\
\hline 24 & 9844195 x CoA 7602 & 27 & 16 & 52 & 5 & 14 & 3 \\
\hline 25 & 984727 x 984843 & 16 & 13 & 16 & 0 & 0 & 0 \\
\hline 26 & 984819 x Co 1148 & 31 & 11 & 60 & 2 & 16 & 3 \\
\hline 27 & 985040 x Co 1148 & 44 & 11 & 5 & 3 & 3 & 3 \\
\hline 28 & 985735 x Co 62198 & 9 & 13 & 9 & 0 & 0 & 0 \\
\hline 29 & 985931 x Co 775 & 36 & 30 & 58 & 5 & 16 & 5 \\
\hline 30 & 986046 x Co 775 & 28 & 31 & 17 & 11 & 8 & 5 \\
\hline 31 & 986095 x Co 62198 & 37 & 57 & 2 & 28 & 0 & 0 \\
\hline 32 & 986095 x Co 94008 & 17 & 31 & 45 & 5 & 5 & 3 \\
\hline 33 & 986140 x Co 1148 & 17 & 17 & 0 & 0 & 0 & 0 \\
\hline 34 & 9869110 x Co 1148 & 25 & 27 & 55 & 11 & 11 & 3 \\
\hline 35 & 9869110 x Co 62198 & 15 & 39 & 33 & 6 & 9 & 0 \\
\hline 36 & 987032 x Co 93009 & 37 & 25 & 87 & 12 & 28 & 13 \\
\hline 37 & 987080 x Co 1148 & 41 & 8 & 55 & 5 & 23 & 6 \\
\hline 38 & 987124 x Co 775 & 19 & 55 & 8 & 9 & 3 & 0 \\
\hline \multirow[t]{2}{*}{39} & 9871144 x Co 775 & 40 & 22 & 11 & 8 & 5 & 3 \\
\hline & Mean & 25 & 32 & 35 & 7 & 10 & 3 \\
\hline
\end{tabular}

YLD - Clump yield (kg) SUC-Sucrose (\%) RRS-Red rot resistance 
The presence of substantial levels of additive genetic variance (horizontal resistance) in the population signifies the fact that resistance break down, a consequence of vertical resistance, could be avoided and stable resistance achieved. This may be due to the involvement of $S$. spontaneum in the parental clones which impart horizontal resistance to their progenies. Natarajan et al. (2001b) reported that, an increase in $S$. spontaneum chromosome in the progenies increases horizontal resistance component of resistance.

A natural phytosystem builds up horizontal resistance and the scope for evolution of vertical resistance is very much limited since it leads to the death of both the host and pathogen. S. spontaneum being a natural phytosystem with a contiguous distribution in the red rot endemic areas together with its ability to propagate naturally by both seed and vegetative means, forms an ideal candidate for evolution and maintenance of horizontal resistance. However, during the course of breeding sugarcane varieties for red rot resistance employing specific isolates of the pathogen, there is a possibility of breeder and pathologist unwittingly shifting the host-pathogen system from one of HR (horizontal resistance)-friendly to VR (vertical resistance)-friendly. This has been very well established in other crops and there are enough indications in sugarcane as well against red rot.

Natarajan et al. (2001b) also reported that, crosses involving susceptible parents may tend to produce resistant progenies with stable resistance due to additive genetic action. In the present study also, two crosses involving susceptible parents viz., 971235 [S] x Co 1148 [S] and Co 88028 [S] X Co775 [S] produced resistant progenies to the tune of 30 per cent and 28 per cent respectively (Table 3 ). These transgressive segregants are the products of additive genetic action and are bound to show stable resistance (horizontal resistance). Such transgressive segregants that have arisen from the susceptible parents on both sides can also be used as potential genetic stocks in resistance breeding programmes for imparting race non-specific resistance.

\section{Economic types}

A breeding programme would have served its purpose well if it brings forth economically superior types apart from generating useful information. Since sugarcane is exploited commercially as a clone, the rationale for family selection is not to produce superior families with commercial value, but rather to identify families with a higher frequency of superior clones (Kimbeng and Cox, 2003). The top scoring families for yield, sucrose per cent, red rot resistance, combination of yield with sucrose, yield with red rot resistance and families combining all the three characters are presented in the Table 5. 


\section{Table 05 : Superior families identified for important traits}

\begin{tabular}{|c|c|c|c|c|c|c|}
\hline \multirow{2}{*}{$\begin{array}{c}\text { S. } \\
\text { No. }\end{array}$} & \multicolumn{6}{|c|}{ Families } \\
\hline & YLD & SUC & RRS & YLD + SUC & YLD + RRS & YLD + SUC + RRS \\
\hline 1 & $\begin{array}{l}\mathrm{CoH} 110 \\
\mathrm{x} 986179\end{array}$ & $\begin{array}{l}971236 \\
\text { x Co } 62198\end{array}$ & $\begin{array}{l}987032 \\
\text { x Co } 93009\end{array}$ & $\begin{array}{l}986095 \\
\text { x Co } 62198\end{array}$ & $\begin{array}{l}987032 \\
\text { x Co } 93009\end{array}$ & $\begin{array}{l}987032 \\
\text { x Co } 93009\end{array}$ \\
\hline 2 & $\begin{array}{l}\text { Co } 98003 \\
\text { x } 971862\end{array}$ & $\begin{array}{l}971235 \\
\text { x Co } 62198\end{array}$ & $\begin{array}{r}\text { RS 93-2182 } \\
\text { x Co } 93009\end{array}$ & $\begin{array}{l}\text { Co } 85002 \\
\text { x } 971862\end{array}$ & $\begin{array}{l}\mathrm{CoH} 110 \\
\mathrm{x} 986179\end{array}$ & $\begin{array}{l}\text { Co } 85002 \\
\text { x } 971862\end{array}$ \\
\hline 3 & $\begin{array}{l}985040 \\
\text { x Co } 1148\end{array}$ & $\begin{array}{l}\text { Co } 85002 \\
x 971862\end{array}$ & $\begin{array}{l}\mathrm{CoH} 110 \\
\mathrm{x} 984843\end{array}$ & $\begin{array}{l}971236 \\
\text { x Co } 62198\end{array}$ & $\begin{array}{l}\text { Co } 98003 \\
x 971862\end{array}$ & \\
\hline 4 & $\begin{array}{l}987080 \\
\text { x Co } 1148\end{array}$ & $\begin{array}{l}\text { Co } 86010 \\
\text { x Co } 775\end{array}$ & $\begin{array}{l}984819 \\
\text { x Co } 1148\end{array}$ & & & \\
\hline 5 & $\begin{array}{l}971144 \\
\text { x Co } 775\end{array}$ & $\begin{array}{l}\mathrm{CoH} 76 \\
\mathrm{x} 985094\end{array}$ & $\begin{array}{l}\text { CoM } 9220 \\
\times 987001\end{array}$ & & & \\
\hline
\end{tabular}

YLD - Clump yield (kg) SUC-Sucrose (\%) RRS - Red rot resistance

\section{CONCLUSIONS}

The present investigation has identified a large number of promising selections for yield, quality and red rot resistance for further testing and release for commercial cultivation and some specific cross combinations for yield, quality and red rot resistance for further exploitation in breeding programme. The specific crosses viz., 987032 x Co 93009 and Co 85002 x 971862 identified for the combination of all the three characters could be utilized to identify outstanding progenies combining yield, quality and resistance to red rot disease in future breeding programmes.

\section{REFERENCES}

Arceneaux, G. (1965). Cultivated sugarcanes of the world and their botanical derivation. Proceedings of International Society of Sugar Cane Technologists, 12, pp.844-854

Barber, C.A. (1901). Sugarcane disease in Godawari and Ganjam Districts. Madras Dept. Land Records and Agricultural Bullettin, 43, pp.181-194

Barber, C.A. (1920). The origin of sugarcane. International Sugar Journal, 22, pp. 249-251.

D'Hont, A., P.S. Rao, P. Feldmann, L. Grivel, N.I. Faridi, G.O.Taylor, and J.C. Gaszmann. (1995). Identification and characterization of sugarcane intergeneric 
hybrids, Saccharum officinarum x Erianthus arundinaceus, with molecular markers and DNA in situ hybridization. Theoretical and Applied Genetics, 91 pp. 320-326.

Kimbeng, C.A. and M.C. Cox. (2003). Early generation selection of sugarcane families and clones in Australia, A review. Journal of American Society of Sugarcane Technologists, 23, pp. 20-39.

Mohanraj, D., P. Padmanaban, R. Viswanathan, and K.C. Alexandar. (1994). Rapid evaluation of resistance against red rot disease of sugarcane under controlled conditions. (in) Proceedings of National Symposium on Ultrastructure, Cytology, Sexuality and Variability in plant Pathogens held during 24-27 January 1994 by Indian Phytopathological Society at Tamil Nadu Agricultural University, Coimbatore, pp. 8-9.

Mohanraj, D., P. Padmanaban, R. Viswanathan, and K.C. Alexandar. (1997). Sugarcane screening for red rot resistance. Sugarcane International, 3, pp.18-23.

Natarajan, U.S. (1984). Studies on progeny performance and combining ability in sugarcane in relation to parental divergence. (Ph.D. Thesis. TNAU, Coimbatore)

Natarajan U.S., T.C. Ramana Rao, N. Balasundaram, K. Palanichamy and B.K Tripathi (1998). Red rot resistance in sugarcane-a critique. Sugar Cane, 1, pp.11-14.

Natarajan, U.S., N. Balasundaram, T.C. Ramana Rao, P. Padmanaban, D. Mohanraj, S. Karthigeyan, R. Kannan, and S. Damodaran. (2001a). Red rot resistance in sugarcane in terms of vertical and horizontal resistance. Abst. Diamond Jubilee Symp., Hundred years of Post-Mendelian Genetics and Plant Breeding -Retrospect and prospects, p. 106.

Natarajan, U.S., N. Balasundaram, T.C. Ramana Rao, P. Padmanaban, D. Mohanraj, S. Karthigeyan, and S. Damodaran. (2001b). Role of Saccharum spontaneum in imparting stable resistance against sugarcane red rot. Sugarcane International, pp. 17-20.

Parthasarathy, N. (1946). The probable origin of North Indian Sugarcanes. Journal of Indian Botanical Society, (M.O.P. Iyengar Commemorative volume), pp.133-150.

Venkatraman, T.S. (1938). Hybridization in and with the genus Saccharum. Presidential address. Indian Science Congress, pp. 53.

Viswanathan, R., D. Mohanraj, and P. Padmanaban. (1998). Comparison of three testing methods for evaluation of resistance to red rot caused by Colletotrichum falcatum in sugarcane (Saccharum officinarum). Indian Journal of Agricultural Sciences, 68 (4), pp.226-230. 